\title{
Internal Model Loss Minimization Control of Permanent Magnet Synchronous Machine
}

\author{
O. Babayomi ${ }^{\mathrm{a}, *}$, A. Balogun ${ }^{\mathrm{b}}$ \\ ${ }^{a}$ Centre for Space Transport \& Propulsion, National Space Research and Development Agency, Abuja, NIGERIA. \\ ${ }^{b}$ Department of Electrical and Electronics Engineering, University of Lagos, Lagos State, NIGERIA.
}

\begin{abstract}
Electric drives are very useful in propelling the wheels of hybrid electric vehicles (HEVs). They also play a central function in the electric power steering (EPS). This paper describes studies carried out on the efficiency optimization of an interior permanent magnet synchronous machine (IPMSM) for application in the EPS. An analytic lossminimization algorithm for an IPMSM was derived and the optimization problem took into consideration copper, iron and stray losses. The proposed loss minimization algorithm is simple and cost effective to implement. From the simulations carried out, significant efficiency gains are possible with this model. The internal model control (IMC) method was employed to achieve current and speed control with acceptable sensitivity to machine parameters.
\end{abstract}

Keywords: loss minimization, interior permanent magnet synchronous motor (IPMSM), electric power steering, internal model control (IMC), sensitivity analysis

\section{INTRODUCTION}

Improving the fossil fuel economy of transportation is one of the effective means to reduce the carbon-footprint of transportation. This translates to diminishing the dependence of road, air and water-based vehicles on fossil fuels. This is already practically being achieved through several technologies including chemical, electrical and mechanical principles. Replacing combustion engines and hydraulic means of actuation with more efficient electric drives (controlled with lossminimization schemes) is an electrical strategy of energy conservation.

Loss minimization can be carried out at the machine design level and through the control of the operation of the electric drive. At the machine design level, finite element analysis has been applied to examine the causes of iron losses and reduce them. The results of these studies reveal that harmonic air-gap flux components, large rotational components of flux density and iron losses in the rotor near the air gap are factors that are responsible for iron losses in interior permanent magnet synchronous motor (IPMSM) operating in the flux-weakening mode [1-4]. These losses are reducible by designing the machine with flat stator teeth [5].

When loss minimization is carried out with the aid of a machine controller, significant energy savings can also be made. From past investigations,

${ }^{*}$ Corresponding author (Tel: +234 (0)1 545 3343)

Email addresses: babayomi@ieee.org (O. Babayomi), obalogun@unilag.edu.ng (A. Balogun) several methods have been employed to achieve this goal. Junggi Lee [6] employed approximating polynomials to solve the fourth order equation resulting from a constrained optimization problem. Particle Swarm Optimization has also been employed in the solution of the optimization problem [7]. However, in these two studies, only copper and iron losses were considered, while the stray loss was neglected.

Efficiency optimization was carried out in [8] by employing the high efficiency characteristic of machines at unity power factor. The loss equation employed by Morimoto et al. [9] was a function of copper and iron losses but did not capture stray losses. This problem was also solved using look-up tables that require high storage [10], maximum torque per ampere (MTPA) [11] and online lossminimization algorithms [12, 13].

The main distinction between this study and others is that the loss minimization analysis captures the effect of stray loss. In addition, we have carried out an extensive sensitivity analysis of the internal model control (IMC) method. The paper delineates the loss minimization analysis in Section 2, introduces the internal model control method in Section 3 and describes the sensitivity analysis in Section 4. Results are shown and explained in Section 5.

\section{LOSS MINIMIZATION OF PMSM}

The dynamics of the stator voltage of the IPMSM machine in quadrature (q)-axis and direct (d)-axis rotor reference frame are given in Eq. (1) and (2) respectively. The electromagnetic torque is given in Eq. (3). 


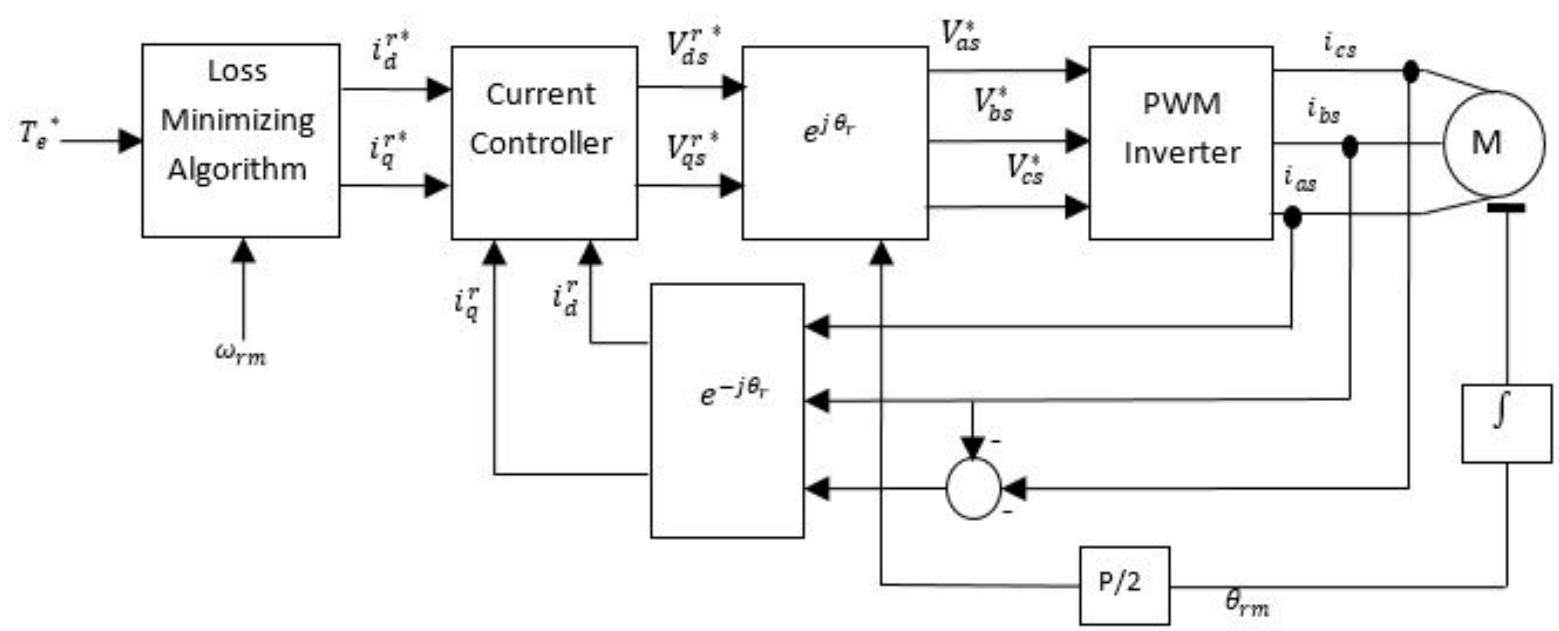

Figure 1: Instantaneous torque control of an interior permanent magnet synchronous machine.

$$
\begin{gathered}
V_{q s}^{r}=R_{s} i_{q}^{r}+\omega_{r} \lambda_{d s}^{r}+p L_{s} i_{q}^{r} \\
V_{d s}^{r}=R_{s} i_{d}^{r}+\omega_{r} \lambda_{q s}^{r}+p\left(L_{d} i_{d}^{r}+\lambda_{f}\right) \\
T_{e}=\frac{3}{2} \frac{p}{2}\left[\left(L_{d}-L_{q}\right) i_{d}^{r} i_{q}^{r}+\lambda_{f} i_{q}^{r}\right]
\end{gathered}
$$

where $L_{d}=L_{l s}+L_{m d} ; L_{q}=L_{l s}+L_{m q} ; \lambda_{q s}^{r}=L_{s} i_{q}^{r}$ and $\lambda_{d s}^{r}=L_{s} i_{q}^{r}+\lambda_{f}$.

The loss minimization of the IPMSM is an optimization problem with a goal to determine the stator command currents that will produce a least real power loss regime during operations of the machine. Operations at such least loss regime will enable the IPMSM to produce a maximum torque output, which ultimately achieves efficiency optimized operation. Thus, as illustrated in Fig. 1, we seek an optimal pair of $d$-axis and $q$-axis stator currents $i_{d}^{r}, i_{q}^{r}$ for a given torque reference and speed, while taking all losses that occur in the machine into account.

The losses in an IPMSM are iron, copper and stray which are defined by Eq. (4) to (6) respectively.

$$
p_{f e}=c_{f e} \omega^{\gamma}\left(\lambda_{d}^{2}+\lambda_{q}^{2}\right)
$$

where $c_{f e}=$ iron loss coefficient [2].

$$
\begin{gathered}
p_{c u}=\frac{3}{2} R_{s}\left(i_{q}^{r}+i_{d}^{r}\right) \\
p_{s}=c_{s} \omega^{2}\left(i_{q}^{r}+i_{d}^{r}\right)
\end{gathered}
$$

The sum total of Eq. (4), Eq. (5) and Eq. (6) is set as the objective (or cost) function in this paper. Therefore, the objective function for the constrained optimization problem is given in Eq. (7), which is subject to constraints in Eq. (8) and Eq. (9).

$$
\begin{aligned}
& p_{t}=\frac{3}{2} R_{s}\left(i_{q}^{2}+i_{d}^{2}\right)+c_{f e} \omega^{\gamma}\left(\lambda_{d}^{2}+\lambda_{q}^{2}\right)+c_{s} \omega^{2}\left(i_{q}^{2}+i_{d}^{2}\right) \\
& =\left(\frac{3}{2} R_{s}+c_{s} \omega^{2}\right)\left(i_{q}^{2}+i_{d}^{2}\right)+c_{f e} \omega^{\gamma}\left(\lambda_{d}^{2}+\lambda_{q}^{2}\right) \\
& =Q\left(i_{q}^{2}+i_{d}^{2}\right)+R\left[\left(L_{d} i_{d}+\lambda_{f}\right)^{2}+L_{q}^{2} i_{q}^{2}\right]
\end{aligned}
$$

where $Q=\left(\frac{3}{2} R_{s}+c_{s} \omega^{2}\right)$ and $R=c_{f e} \omega^{\gamma}$

$$
K\left[\lambda_{f} i_{q}+L_{\Delta} i_{d} i_{q}\right]-T_{e}=0
$$

where $K=\frac{3 P}{2}$ and $L_{\Delta}=L_{d}-L_{q}$.

$$
i_{q}^{2}+i_{d}^{2} \leq i_{m}^{2}
$$

Hence, the minimum loss occurs when the Jacobi developed in Eq. (10) is set to zero, from which the following fourth-order Eq. (11) is derived [14]. The exact solution to $i_{q}$ that corresponds to the optimal operating regime can be obtained by solving Eq. (11).

$$
\left|\begin{array}{ll}
\frac{\partial T_{e}}{\partial i_{q}} & \frac{\partial T_{e}}{\partial i_{d}} \\
\frac{\partial P_{t}}{\partial i_{q}} & \frac{\partial P_{t}}{\partial i_{d}}
\end{array}\right|=0
$$

$$
\begin{aligned}
& K^{2} L_{\Delta}^{2}\left(Q L_{\Delta}+R L_{\Delta} L_{d}^{2}+Q \lambda_{f}+R \lambda_{f} L_{q}^{2}\right) i_{q}^{4} \\
& +\lambda_{f}^{2} K^{2} L_{\Delta}\left[R L_{\Delta} L_{d}-\left(Q+R L_{d}^{2}\right)\right] i_{q}^{2} \\
& +T_{e} K \lambda_{f} L_{\Delta}\left[1\left(Q+R L_{d}^{2}\right)-R L_{\Delta} L_{d}\right] i_{q} \\
& -\left(Q+R L_{d}^{2}\right) L_{\Delta} T_{e}^{2}=0
\end{aligned}
$$

Figure 2 shows the plots of total power loss against q-axis current at a speed of 1200rpm. The plots show that minimum loss occur at 5.6A, 6.6A and $9.8 \mathrm{~A}$ when electromagnetic torque is $4 \mathrm{Nm}, 6$ $\mathrm{Nm}$ and $10 \mathrm{Nm}$ respectively. These values of Iq correspond to the magnitudes of current obtained from the minimum current expression in Eq. (11). 


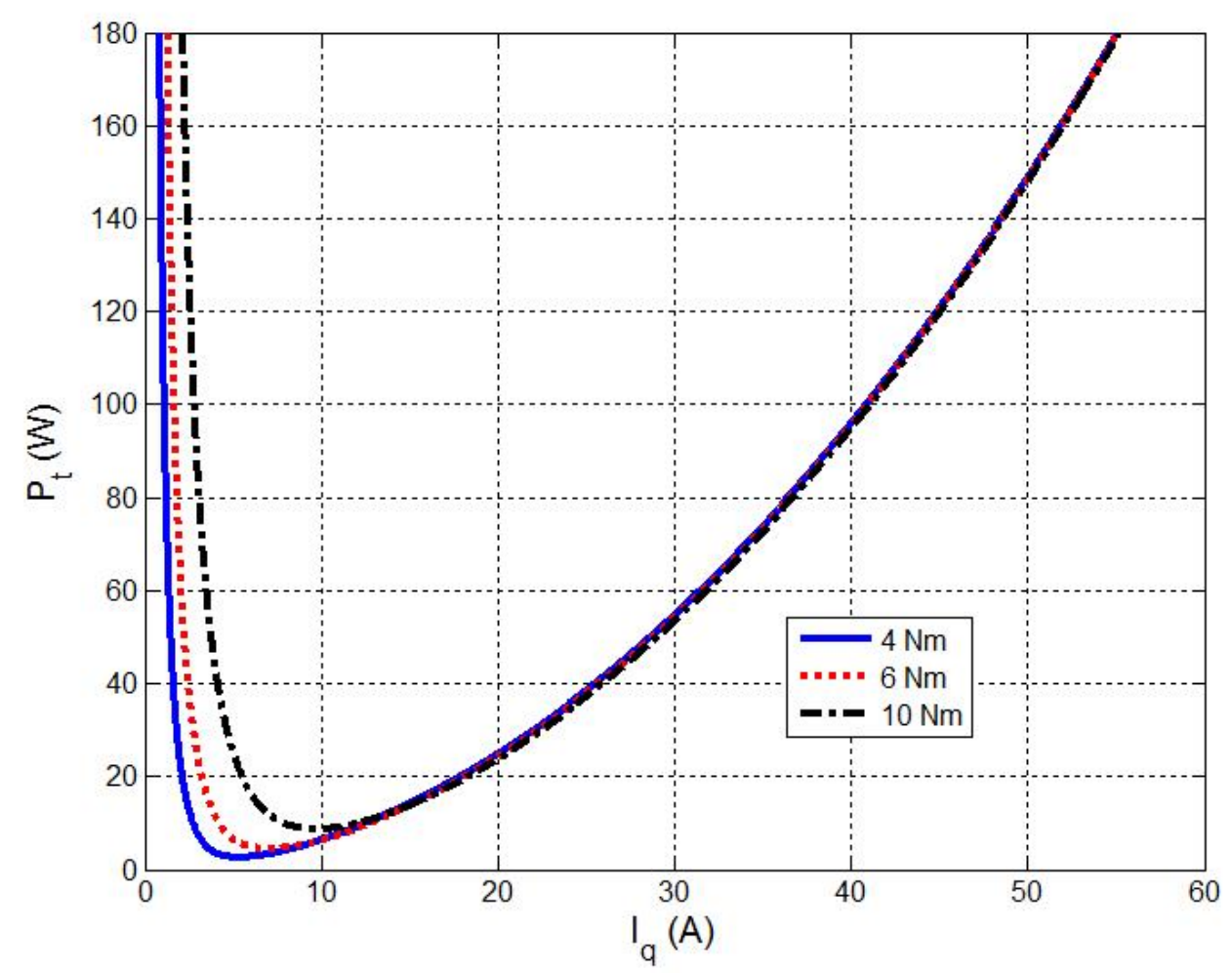

Figure 2: Plots of total power loss showing the points of minimum loss.

\subsection{Improved Lower Order Solution}

The typical digital signal processor used for the control of AC drives has limited memory capacity. Therefore, the algorithm to solve a fourthorder equation will increase the cost of the system. Hence, we will compromise exactness for a solution within acceptable accuracy, while not increasing the cost of the control hardware.

The procedure will involve utilizing the approximate second order equation and correcting it by adding the error due to the approximation. Since $L_{\Delta}$ is of the order $10^{-3}, L_{\Delta}^{2}$ can be taken as negligible, resulting in the following approximate solution

$$
K^{2} \lambda_{f}^{2} i_{q}^{2}-2 T_{e} K \lambda_{f} i_{q}+T_{e}^{2}=0
$$

Consider the Taylor expansion, viz,

$$
f(x+h)=f(x)+\frac{d f(x)}{d x} h+\frac{d^{2} f(x)}{d x^{2}} \frac{h^{2}}{2 !}+\epsilon
$$

where $\epsilon$ is the truncation error, which is $O\left(h^{3}\right)$.

Therefore,

$$
\epsilon=\frac{d^{3} f(x)}{d x^{3}} \frac{h^{3}}{3 !}
$$

For the problem under consideration, $f$ is the $4^{\text {th }}$ order equation in Eq. (11).

$$
\begin{aligned}
& f=K^{2} L_{\Delta}\left(Q L_{\Delta}+R L_{\Delta} L_{d}^{2}+Q \lambda_{f}+R \lambda_{f} L_{q}^{2}\right) i_{q}^{4} \\
& +\lambda_{f}^{2} K^{2}\left[R L_{\Delta} L_{d}-\left(Q+R L_{d}^{2}\right)\right] i_{q}^{2} \\
& +T_{e} K \lambda_{f}\left[2\left(Q+R L_{d}^{2}\right)-R L_{\Delta} L_{d}\right] i_{q}-\left(Q+R L_{d}^{2}\right) T_{e}^{2}
\end{aligned}
$$

Thus from Eq. (14),

$$
\epsilon=4 h^{3} K^{2} L_{\Delta}\left(Q L_{\Delta}+R L_{\Delta} L_{d}^{2}+Q \lambda_{f}+R \lambda_{f} L_{q}^{2}\right) i_{q}
$$

From Eq. (16),

$$
h=\sqrt[3]{\frac{i_{q}-i_{q-}}{4 K^{2} L_{\Delta}}\left(Q L_{\Delta}+R L_{\Delta} L_{d}^{2}+Q \lambda_{f}+R \lambda_{f} L_{q}^{2}\right) i_{q}}
$$

where $i_{q}=$ exact solution from 4 th order equation and $i_{q-}=$ approximate solution from $2^{\text {nd }}$ order equation. Since in a real application, the DSP memory will be insufficient to store the algorithm for the exact solution to the $4^{\text {th }}$ order equation, it might be impractical to solve Eq. (17) digitally. Thus, we resort to storing the following plot in Fig. 3 in a lookup table in the microprocessor, from which appropriate values of $h$ will be selected for instantaneous pairs of speed and torque.

\subsection{Loss Minimization Algorithm}

1. Solve for

$$
i_{q-}=\frac{E \pm \sqrt{E^{2}-4 D T_{e}^{2}}}{2 D}
$$




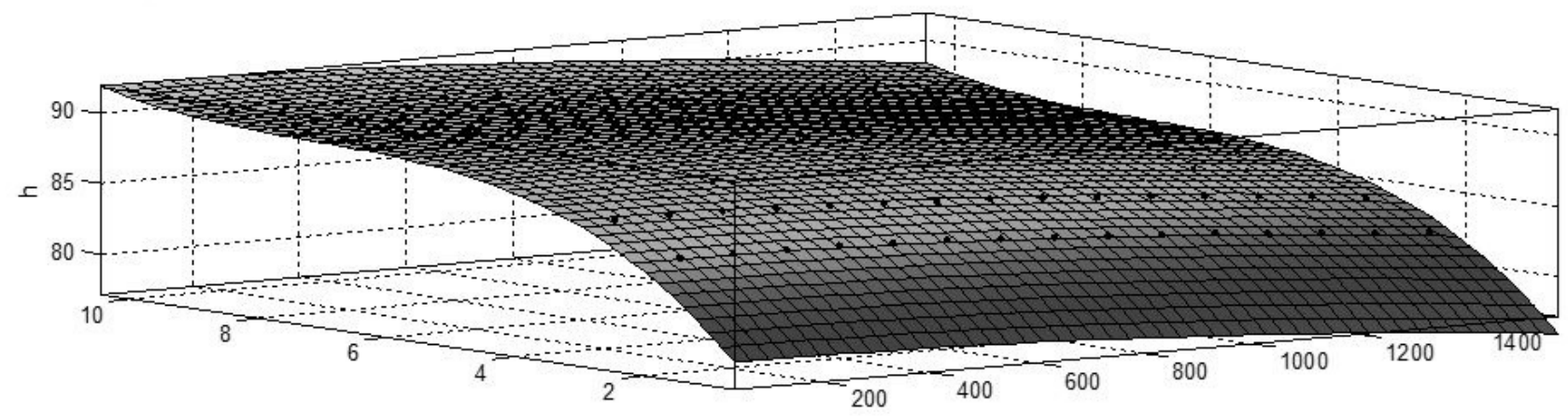

Torque (Nm)

Speed ( $\mathrm{rad} / \mathrm{s})$

Figure 3: Plot of $h$ against torque and speed.

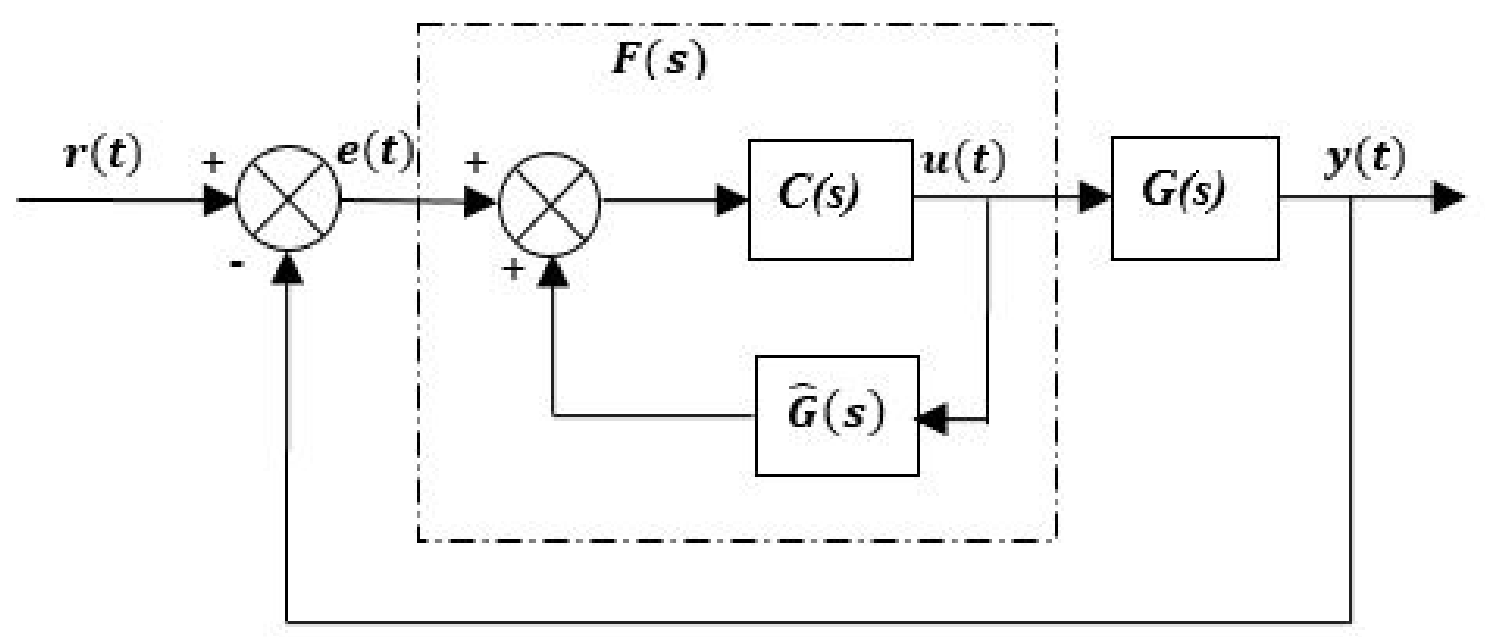

Figure 4: Classical model of internal model control.

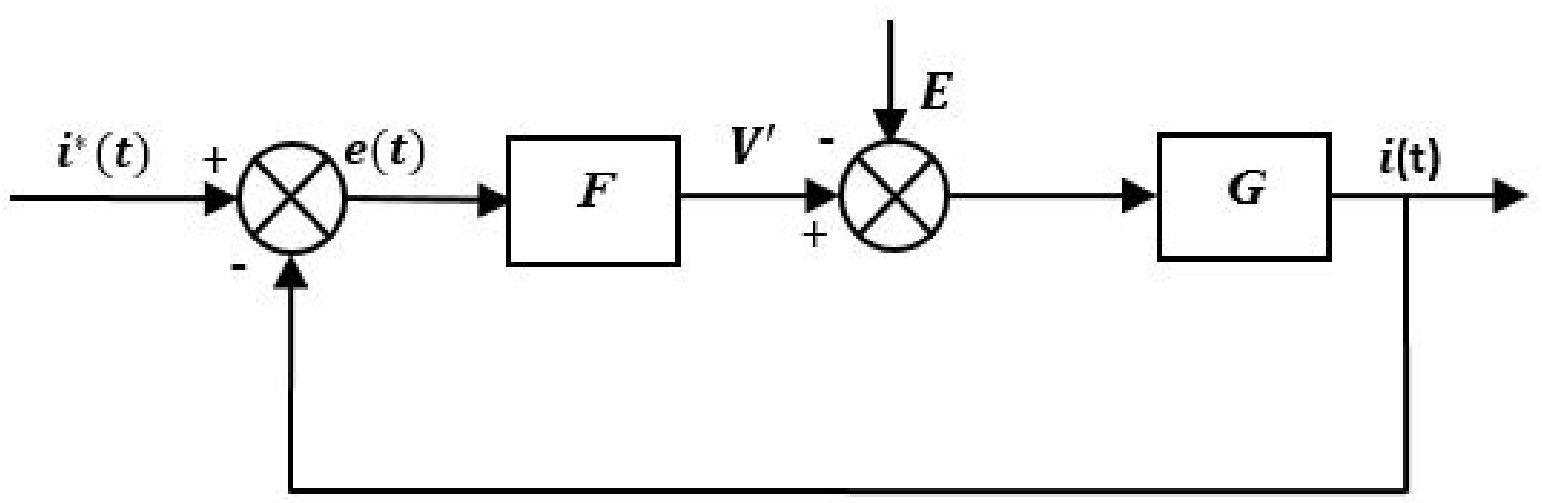

Figure 5: Current control scheme [15]. 
where $D=\frac{9 \lambda_{f}^{2} P^{2}}{4} ; E=2 T_{e} K \lambda_{f}$.

2. Correct the error in $i_{q}$ as follows:

$$
\begin{aligned}
i_{q_{+}}= & i_{q^{-}}+4 h^{3} K^{2} L_{\Delta}\left(Q L_{\Delta}+R L_{\Delta} L_{d}^{2}\right. \\
& \left.+Q \lambda_{f}+R \lambda_{f} L_{q}^{2}\right) i_{q-}
\end{aligned}
$$

or

$$
\begin{aligned}
i_{q+}= & i_{q-}\left[1+4 h^{3} K^{2} L_{\Delta}\left(Q L_{\Delta}\right.\right. \\
& \left.\left.+R L_{\Delta} L_{d}^{2}+Q \lambda_{f}+R \lambda_{f} L_{q}^{2}\right)\right]
\end{aligned}
$$

3. Calculate the $d$-axis current as

$$
i_{d}=\frac{T_{e}-K \lambda_{f} i_{q+}}{K L_{\Delta} i_{q}}
$$

where $K=\frac{3 P}{2}$

\section{INTERNAL MODEL CONTROL OF AN IPMSM}

The general principle used in the internal model control of an IPMSM will be described in the following discussion. The plant to be controlled is illustrated in Fig. 4. $\widehat{G(s)}$ is the internal model of plant $G(\mathrm{~s})$ and $C(\mathrm{~s})$ is the internal model controller [16].

For the IPMSM of interest, $r(t)=\left[i_{d}^{*}, i_{q}^{*}\right]^{t}, u(t)=$ $\left[v_{d}, v_{q}\right]^{T}$ and $y(t)=\left[i_{d}, i_{q}\right]^{T}$.

From Fig. 3,

$$
F(s)=\frac{C(s)}{1-C(s) \widehat{G(s)}}=[1-C(s) \widehat{G(s)}]^{-1} C(s)
$$

\subsection{Current Controller Design for IPMSM}

The current controller design will be done in the synchronous frame of reference. Using the internal model control (IMC) method [15], the current controller scheme for the IPMSM is developed using Eqs. (22) and (23).

$$
\begin{aligned}
& v_{q}^{*}=k_{p q} \epsilon+k_{i q} I_{q}+\omega_{r} L_{d} i_{d}-R_{a q} i_{q} \\
& v_{d}^{*}=k_{p d} \epsilon+k_{i d} I_{d}+\omega_{r} L_{q} i_{q}-R_{a d} i_{d}
\end{aligned}
$$

where the last two terms of each equation are the decoupling and active damping terms respectively.

$\epsilon=\left(i_{q}^{*}-i_{q}\right), I_{q, d}=\int \epsilon d \tau, k_{p}=\alpha L_{s}, k_{i} \alpha k_{p}, R_{a}=\mathrm{ac}-$ tive damping and $L_{s}, R_{s}$ are IPMSM model parameters. $\alpha$ represents the bandwidth and is given by $\alpha=\ln 9 / t_{r}$, while $t_{r}$ is the rise time. Equation (24) below is the full form of Eq. (21).

$$
F(s)=\left[\begin{array}{cc}
\left(\alpha L_{d}+\frac{\alpha\left(R_{s}+R_{a d}\right)}{s}\right) & -\omega_{r} L_{q} \\
\omega_{r} L_{q} & \left(\alpha L_{q}+\frac{\alpha\left(R_{s}+R_{a q)}\right.}{s}\right)
\end{array}\right]=0
$$

Comparing Eq. (24) with $K_{P I}$ (the PI controller for $\mathrm{d}$ and $\mathrm{q}$ axes respectively) given in Eq. (25) yields the parameters of the current PI controller, which are given in Eq. (26).

$$
\begin{aligned}
& K_{P I}=\left[\begin{array}{cc}
\left(\alpha K_{p d}+\frac{K_{i d}}{s}\right) & 0 \\
0 & \left(\alpha K_{p d}+\frac{K_{p d}}{s}\right)
\end{array}\right] \\
& d \text {-axis : } \quad K_{p d}=\alpha L_{d}, \quad K_{i d}=\alpha\left(R_{s}+R_{a d}\right) \\
& \left.q \text {-axis : } K_{p d}=\alpha L_{q}, \quad K_{i q}=\alpha\left(R_{s}+R_{a q}\right)\right\}
\end{aligned}
$$

\subsection{Current Controller Coupling Damping}

The IMC current controller of the IPMSM is described by the block diagram in Fig. 5 [15], while Eq. (27) is the machine's transfer function decoupled from cross-coupling terms.

$$
\begin{gathered}
G(s)=\left[\begin{array}{cc}
\frac{1}{\left(s L_{d}+R_{s}+R_{a d}\right)} & 0 \\
0 & \frac{1}{\left(s L_{q}+R_{s}+R_{a q}\right)}
\end{array}\right] \\
E=\left[\begin{array}{cc}
0 & -\omega_{r} L_{q} \\
\omega_{r} L_{q} & 0
\end{array}\right]\left[\begin{array}{l}
i_{d} \\
i_{q}
\end{array}\right]
\end{gathered}
$$

The disturbance due to the load is given in Eq. (28). In order to dampen the disturbance, the damping terms $R_{a d}=\alpha L_{d}-R_{s}$ and $R_{a q}=\alpha L_{q}-R_{s}$ are introduced.

\subsection{Speed Controller Design}

Using the internal model control method, the following discussion outlines the speed controller design [17] and the resulting speed control scheme is shown in Fig. 6. The mechanical dynamics of the IPMSM is governed by:

$$
J \frac{d \omega_{r}}{d t}+B \omega_{r}=N_{p}\left(T_{e}-T_{m}\right)
$$

where $N_{p}=$ number of pole pairs, $B=$ coefficient of viscous damping, $\omega_{r}=$ angular speed in elect. $\mathrm{rad} / \mathrm{s}$ and $T_{e}=$ electromechanical torque.

Assume $T_{m}$ is a frictional load,

$$
T_{m}=B_{m} \omega_{r}
$$

and $B_{m}=$ coefficient of frictional damping.

$$
\Rightarrow K_{p \omega}=\frac{J \alpha_{\omega}}{N_{p}} \text { and } K_{i \omega}=\frac{B \alpha_{\omega}}{N_{p}}
$$




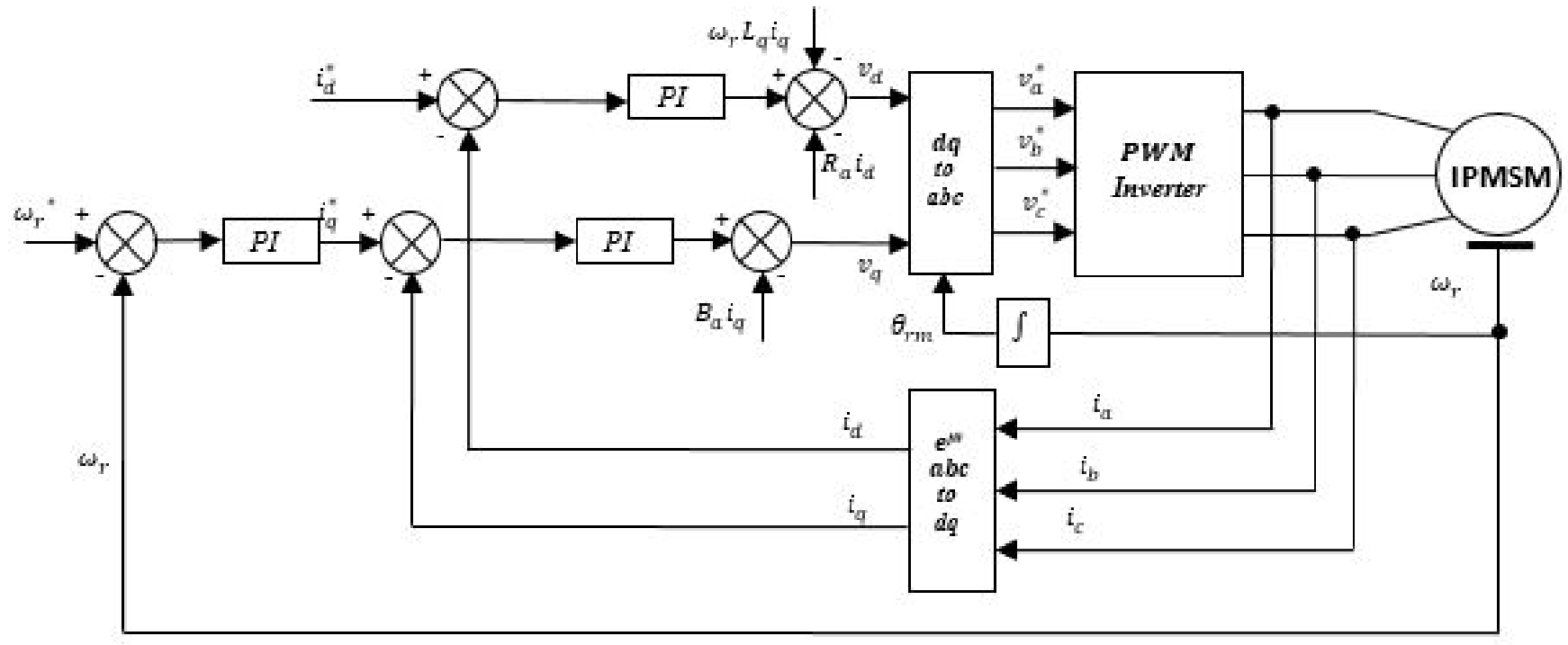

Figure 6: IMC speed control scheme [17].

\section{SENSITIVITY ANALYSIS}

Generally, the developed control scheme may suffer from parameter variation or mismatch from the actual parameters of the machine. The mismatch may vary over the range of operating region of the motor. The ambient temperature can also cause parameter changes in a machine. In this section, the focus is on the sensitivity of the current to changes in the resistive and inductive components of the machine. The sensitivity of current to variation in machine parameters is established using Eq. (32), which is decomposed to Eq. (33).
Expansion of Eq. (33) yield Eq. (34).

$$
i=\frac{G F i^{*}-G E}{(I+G F}=\frac{G F i^{*}-G E}{\left[\begin{array}{cc}
2 & \frac{-\omega_{r} L_{q}}{\left(s L_{d}+R_{s}+R_{a d}\right)} \\
\frac{\omega_{r} L_{d}}{\left(s L_{q}+R_{s}+R_{a q}\right)} & 2
\end{array}\right]}
$$

Hence, the sensitivity of current to resistance $R_{s}$ variations is found by taking partial derivatives of Eq. (34) and because $L_{d}, L_{q}$ are each of order $10^{-3}, L_{d} L_{q}$ is assumed to be negligible.

$$
\begin{gathered}
i=\left[\begin{array}{l}
i_{q} \\
i_{d}
\end{array}\right]=\frac{1}{\Delta}\left[\begin{array}{cc}
2 & \frac{\omega_{r} L_{q}}{\left(s L_{d}+R_{s}+R_{a d}\right)} \\
\frac{-\omega_{r} L_{d}}{\left(s L_{q}+R_{s}+R_{a q}\right)} & 2
\end{array}\right]\left[\begin{array}{c}
\frac{\alpha}{s} i_{q}^{*}+\frac{\omega_{r} L_{q}\left(-\frac{\alpha}{s} i_{d}^{*}+i_{d}\right)}{\left(s L_{d}+R_{s}+R_{a d}\right.} \\
\frac{\alpha}{s} i_{d}^{*}+\frac{-\omega_{r} L_{d}\left(-\frac{\alpha}{s} i_{q}^{*}+i_{q}\right)}{\left(s L_{q}+R_{s}+R_{a q}\right)}
\end{array}\right] \\
{\left[\begin{array}{l}
i_{q} \\
i_{d}
\end{array}\right]=\frac{1}{\Delta}\left[\begin{array}{l}
\frac{2 \alpha}{s} i_{q}^{*}+\frac{2 \omega_{r} L_{q}\left(-\frac{\alpha}{s} i_{d}^{*}+i_{d}\right)}{\left(s L_{d}+R_{s}+R_{a d}\right)}+\frac{\omega_{r} L_{q}}{\left(s L_{d}+R_{s}+R_{a d}\right)}\left[\frac{\alpha}{s} i_{d}^{*}+\frac{\omega_{r} L_{d}\left(\frac{\alpha}{s} i_{q}^{*}+i_{q}\right)}{\left(s L_{q}+R_{s}+R_{a q}\right)}\right. \\
\frac{2 \alpha}{s} i_{d}^{*}+\frac{2 \omega_{r} L_{d}\left(\frac{\alpha}{s} i_{q}^{*}+i_{q}\right)}{\left(s L_{q}+R_{s}+R_{a q}\right)}-\frac{\omega_{r} L_{d}}{\left(s L_{q}+R_{s}+R_{a q}\right)}\left[\frac{\alpha}{s} i_{q}^{*}+\frac{\omega_{r} L_{q}\left(-\frac{\alpha}{s} i_{d}^{*}+i_{d}\right)}{\left(s L_{d}+R_{s}+R_{a d}\right)}\right]
\end{array}\right]}
\end{gathered}
$$

where

$$
\begin{gathered}
\Delta=4+\frac{\omega_{r}^{2} L_{q} L_{d}}{\left(s L_{d}+R_{s}+R_{a d}\right)\left(s L_{q}+R_{s}+R_{a q}\right.} \\
\frac{\partial i_{q}}{\partial R_{s}}=\frac{\alpha \omega_{r} L_{q} i_{d}^{*} s}{4 s^{2}\left(s L_{d}+R_{s}+R_{a d}\right)^{2}}-\frac{\omega_{r} L_{q}\left(-\frac{\alpha}{s} i_{d}^{*}+i_{d}\right)}{2\left(s L_{d}+R_{s}+R_{a d}\right)^{2}}-\frac{\omega_{r} L_{q}}{2\left(s L_{d}+R_{s}+R_{a d}\right)} \frac{\partial i_{d}}{\partial R_{s}} \\
\frac{\partial i_{d}}{\partial R_{s}}=\frac{\alpha \omega_{r} L_{d} i_{q}^{*} s}{4 s^{2}\left(s L_{q}+R_{s}+R_{a q}\right)^{2}}-\frac{\omega_{r} L_{d}\left(\frac{\alpha}{s} i_{q}^{*}+i_{q}\right)}{2\left(s L_{q}+R_{s}+R_{a q}\right)^{2}}+\frac{\omega_{r} L_{d}}{2\left(s L_{q}+R_{s}+R_{a q}\right)} \frac{\partial i_{q}}{\partial R_{s}} \\
\frac{\partial i}{\partial R_{s}}=\left[\begin{array}{l}
\frac{\partial i_{q}}{\partial R_{s}} \\
\frac{\partial i_{d}}{\partial R_{s}}
\end{array}\right]=\left[\begin{array}{l}
\frac{2 Z_{q} \omega_{r} L_{q}}{4 Z_{q} Z_{d}+\omega_{r}^{2} L_{q} L_{q}}\left[\frac{\alpha i_{d}^{*}}{2 Z_{d}}-\frac{\left(-\frac{\alpha}{s}+i_{d}\right)}{Z_{d}}-\frac{\alpha \omega_{r} L_{d} i_{q}^{*}}{4 s Z_{q}^{2}}+\frac{\omega_{r} L_{d}\left(\frac{\alpha}{s} i_{q}^{*}+i_{q}\right)}{2 Z_{q}^{2}}\right] \\
\frac{2 Z_{q} Z_{d}}{4 Z_{d}+\omega_{r}^{2} L_{d} L_{q}}\left[\frac{\alpha i_{q}^{*}}{2 Z_{q}}-\frac{\left(\frac{\alpha}{s}+i_{q}\right)}{Z_{q}}+\frac{\alpha \omega_{r} L_{q} i_{d}^{*}}{4 s Z_{d}^{2}}-\frac{\omega_{r} L_{q}\left(-\frac{\alpha}{s} i_{d}^{*}+i_{d}\right)}{2 Z_{d}^{2}}\right]
\end{array}\right]
\end{gathered}
$$


Eq. (37) was obtained by solving Eqs. (35) and (36) simultaneously, where $Z_{q}=s L_{q}+R_{s}+R_{a q}$ and $Z_{d}=s L_{d}+R_{s}+R_{a d}$.
Similarly, the partial derivatives with respect to $d$ - and $q$ - axes components of inductance result in Eqs. (38) to (41), from which we obtain Eq. (42).

$$
\begin{aligned}
\frac{\partial i_{d}}{\partial L_{d}} & =\frac{\omega_{r} L_{d}}{2 Z_{q}} \frac{\partial i_{q}}{\partial L_{d}}+\frac{\omega_{r}}{2 Z_{q}}\left[\frac{\alpha}{2 s} i_{q}^{*}+i_{q}-\frac{\omega_{r} L_{q}}{2 Z_{d}}\left(-\frac{\alpha}{s} i_{d}^{*}+i_{d}\right)\right] \\
\frac{\partial i_{q}}{\partial L_{d}} & =\frac{\omega_{r} L_{q}}{2 Z_{d}} \frac{\partial i_{d}}{\partial L_{d}}+\frac{\omega_{r} L_{q} s}{4 Z_{d}^{2}}\left(\frac{\alpha}{s} i_{d}^{*}-2 i_{d}\right)+\frac{\omega_{r}^{2} L_{q}}{4 Z_{d} Z_{q}}\left(\frac{\alpha}{s} i_{q}^{*}+i_{q}\right) \\
\frac{\partial i_{q}}{\partial L_{q}} & =\frac{\omega_{r} L_{q}}{2 Z_{d}} \frac{\partial i_{d}}{\partial L_{q}}+\frac{\omega_{r}}{2 Z_{d}}\left[-\frac{\alpha}{2 s} i_{d}^{*}+i_{d}+\frac{\omega_{r} L_{d}}{2 Z_{q}}\left(\frac{\alpha}{s} i_{q}^{*}+i_{q}\right)\right]
\end{aligned}
$$

and

$$
\frac{\partial i_{d}}{\partial L_{q}}=\frac{\omega_{r} L_{d}}{2 Z_{q}} \frac{\partial i_{q}}{\partial L_{q}}+\frac{\omega_{r} L_{d} s}{4 Z_{q}^{2}}\left(-\frac{\alpha}{s} i_{q}^{*}-2 i_{q}\right)-\frac{\omega_{r}^{2} L_{d}}{4 Z_{d} Z_{q}}\left(-\frac{\alpha}{s} i_{d}^{*}+i_{d}\right)
$$

$$
\frac{\partial i}{\partial L}=\left[\begin{array}{c}
\frac{\partial i_{q}}{\partial L_{q}} \\
\frac{\partial i_{q}}{\partial L_{d}} \\
\frac{\partial i_{d}}{\partial L_{q}} \\
\frac{\partial i_{d}}{\partial L_{q}}
\end{array}\right]=\left[\begin{array}{c}
\frac{\omega_{r}}{4 Z_{d}}\left(-\frac{\alpha}{s} i_{d}^{*}+2 i_{d}\right)+\frac{\omega_{r}^{2} L_{d}}{4 Z_{q} Z_{d}}\left(\frac{\alpha}{s} i_{q}^{*}+i_{q}\right) \\
0 \\
0 \\
\frac{\omega_{r}}{4 Z_{q}}\left(\frac{\alpha}{s} i_{q}^{*}+2 i_{q}\right)-\frac{\omega_{r}^{2} L_{q}}{4 Z_{q} Z_{d}}\left(\frac{\alpha}{s} i_{q}^{*}+i_{d}\right)
\end{array}\right]
$$

\section{RESULTS}

\subsection{Loss Minimization Results}

Table 1: Pressure drop in selected service pipeline sections (Option 3 ).

\begin{tabular}{ll}
\hline Parameter & Value \\
\hline$c_{f e}$ & 0.0021 \\
$\gamma$ & 1.5 \\
$R_{s}$ & $0.02 \Omega$ \\
$L_{q}$ & $8.6 \mathrm{mH}$ \\
$L_{d}$ & $22.5 \mathrm{mH}$ \\
$\lambda_{f}$ & $0.105 \mathrm{~Wb}$ \\
$I_{m}$ & $60 \mathrm{~A}$ \\
$J$ & $8 \times 10^{-5} \mathrm{kgm}^{2}$ \\
$B$ & $16 \times 10^{-5} \mathrm{~N} . \mathrm{m} . \mathrm{s} / \mathrm{rad}$ \\
\hline
\end{tabular}

The parameters in Table 1 were used for the simulation of a 6-pole permanent magnet synchronous motor with MATLAB/SIMULINK. Figure 7 shows the variation of efficiency with speed and torque in the IPMSM. The efficiency of the machine when $d$-axis current is maintained constant at zero $\left(i_{d}^{*}=0\right.$, as is conventionally done in machine torque control) are compared with results from minimizing the total losses $\left(i_{q}^{*}, i_{d}^{*} \mathrm{opt}\right)$. When the speed is kept constant at $300 \mathrm{rpm}$ and torque is varied from $1 \mathrm{Nm}$ to $10 \mathrm{Nm}$, the loss minimization scheme results in higher efficiency by about $1.5 \%$. When the machine operates at a higher speed of $1000 \mathrm{rpm}$, the efficiency gains are about $0.2 \%$. Although these figures appear insignificant, in applications like electric vehicles, over a long time, the improvement in efficiency results in huge savings in energy.

However, when the torque is maintained constant at 2 and $8 \mathrm{Nm}$ (to test the performance of the control scheme at low and high torque values), the margin in efficiency gains reduces as speed is varied from 200 to $1600 \mathrm{rpm}$. This is expected since losses increase with speed, when torque is maintained constant. As can be seen from Fig. 8, by employing the improved second order algorithm, values of $q$-axis stator currents within $2 \%$ range of the actual values were recorded.

\section{Current Controller Results}

Figure 9 depicts the behaviour of the controller to a step input when the input was stepped at $20 \mathrm{~ms}$. The motor behaviour shows a correlation of both $q$-axis and $d$-axis currents for a design rise time of $10 \mathrm{~ms}$. The $q$-axis and $d$-axis currents followed the input as required without any overshoot.

Figure 10 shows the responses of the motor to pulse inputs with $50 \%$ duty cycle and $q$-axis and $q$-axis currents of $2.5 \mathrm{~A}$ and $-3 \mathrm{~A}$ respectively. The currents followed the input reference as desired with an initial time delay due to saturation.

\subsection{Speed Controller Results}

Speed controller responses are illustrated in Figs. 11(a) and 11(b). For both step and constant input reference speeds, the outputs rose to follow the input. The steepness of the speed response is dictated by the controller rise time.

\subsection{Sensitivity Analysis Results}

Figure 12(a) illustrates the sensitivity of the IMC controlled current to the stator resistance of the IPMSM. Over a range of speed, there is a high level of variation of the current to changes in the resistance at low and high speeds. However, in the region of the operational speed $\omega_{r}, \mathrm{D}$-axis current is insensitive to changes in the resistance. A 


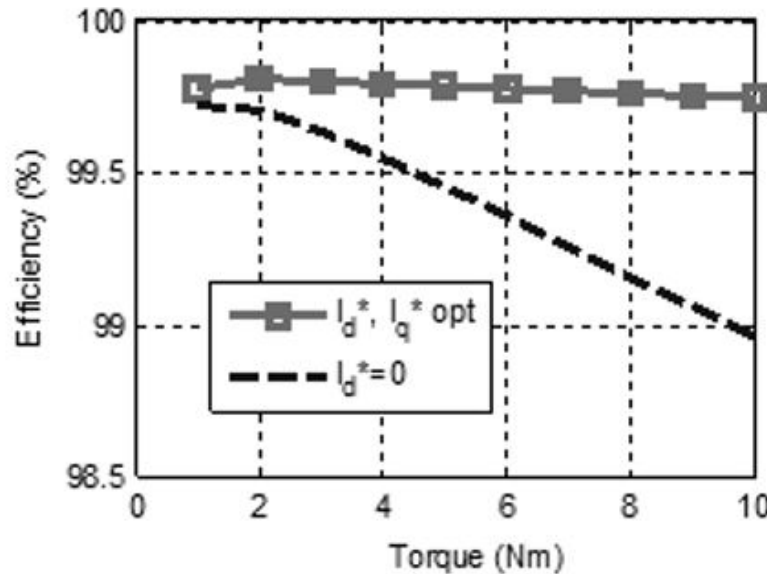

(a) Speed 300rpm

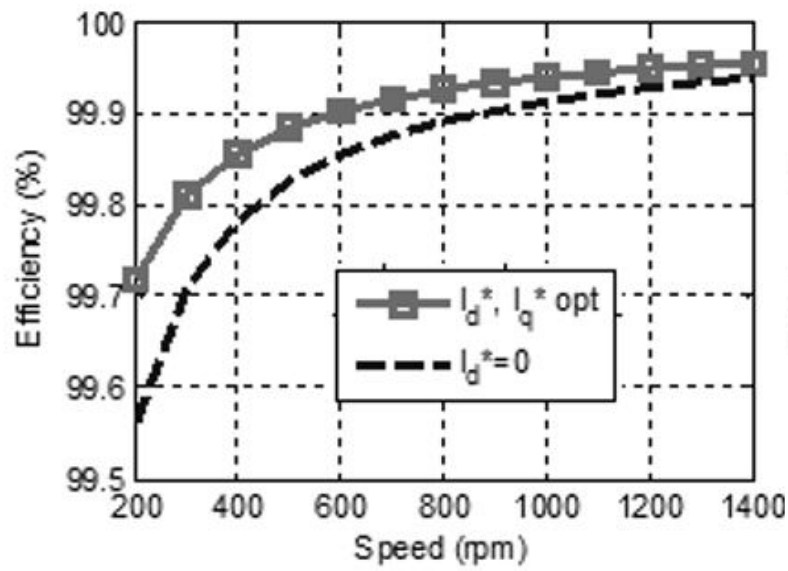

(c) $T_{e}=2 \mathrm{Nm}$

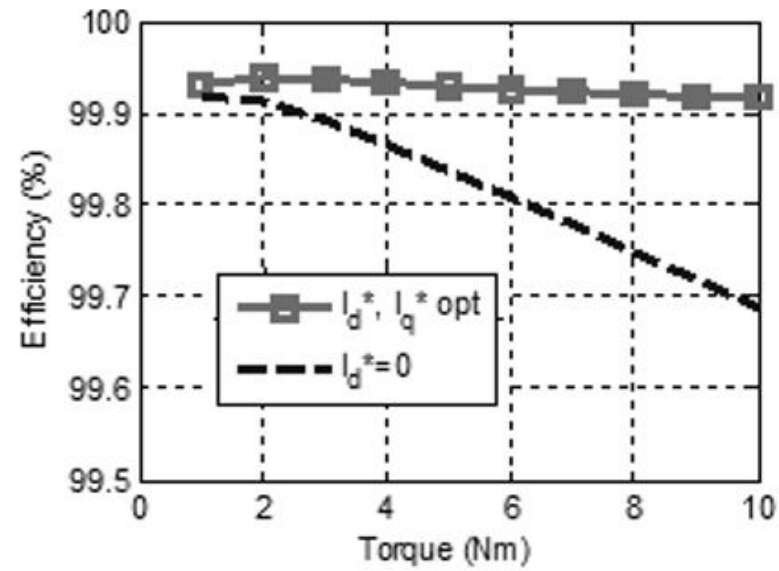

(b) Speed 1000rpm

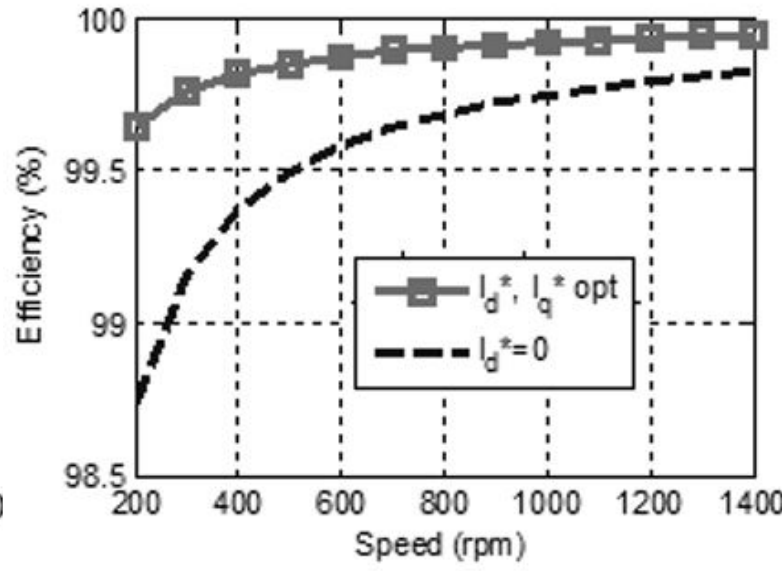

(d) $T_{e}=8 \mathrm{Nm}$

Figure 7: Efficiency improvements in the IPMSM. (a) Speed=300rpm (b) Speed 1000rpm (c) $T_{e}=2 \mathrm{Nm}$ (d) $T_{e}=$ $8 \mathrm{Nm}$. (Curves marked $i_{d}=0$ are for the non-optimized control cases.)

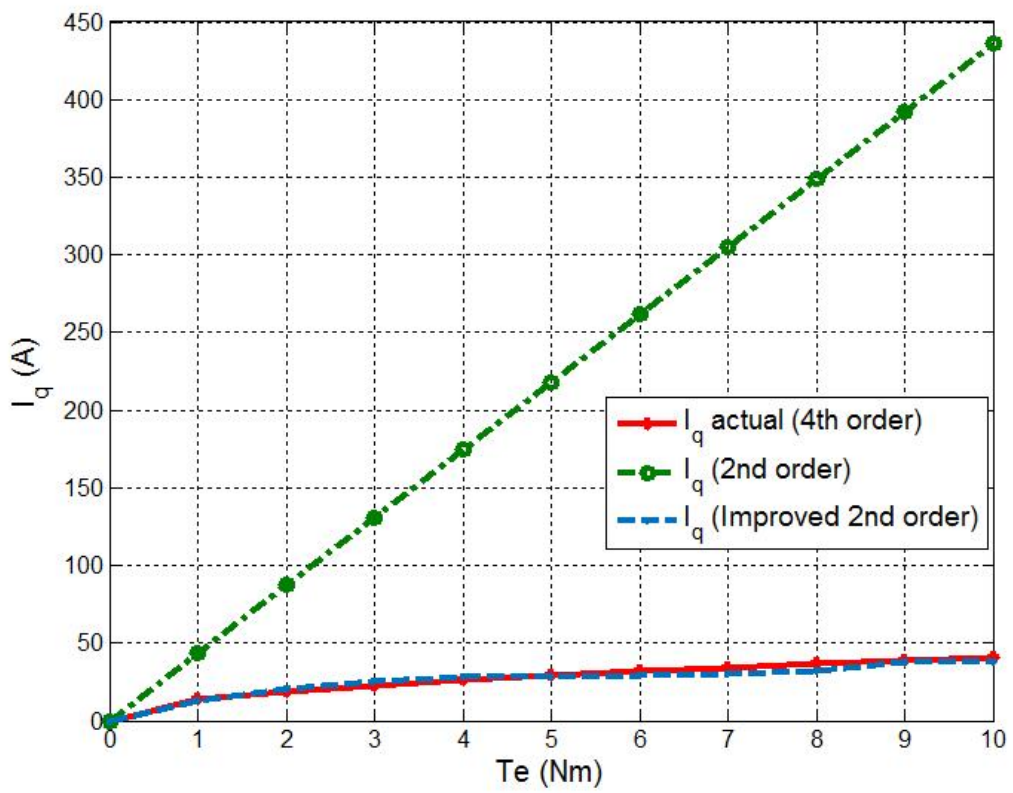

Figure 8: Comparison of actual current with approximations. 


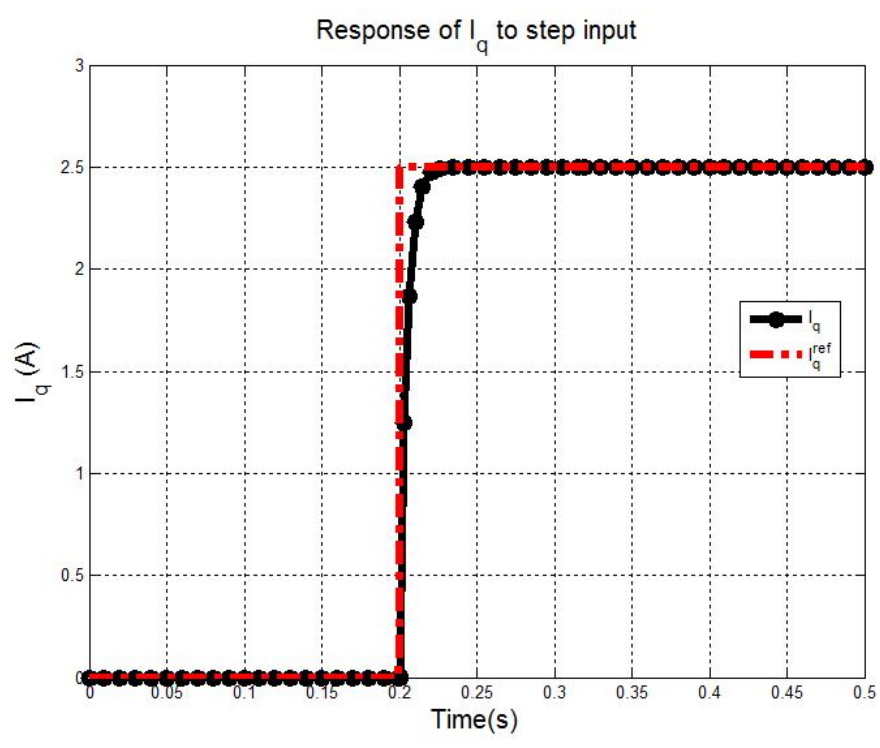

(a) Q-axis current

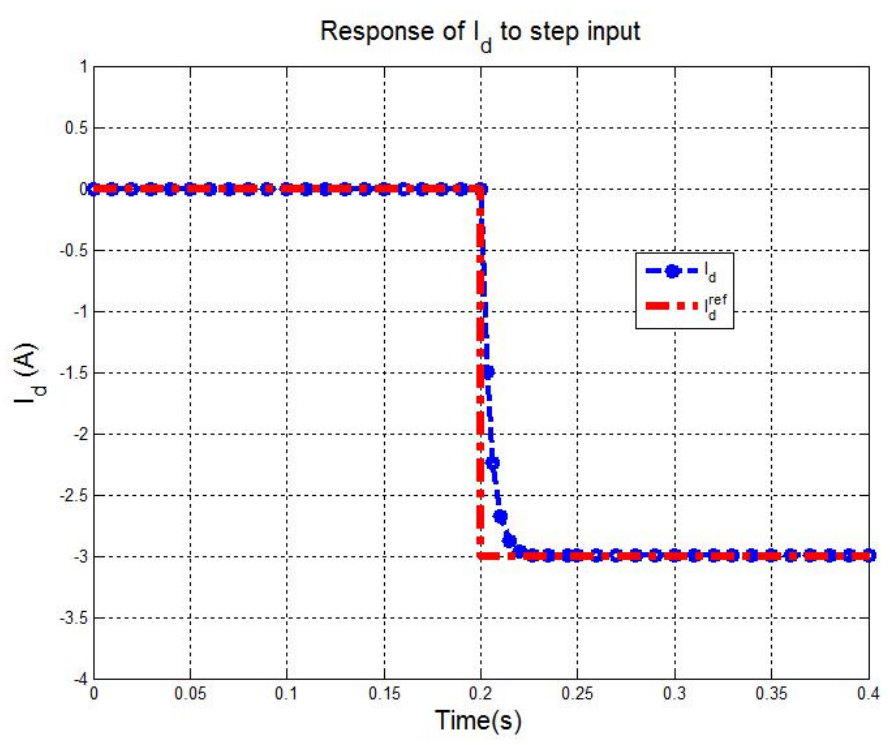

(b) D-axis current response to step input.

Figure 9: (a) Q-axis current (b) D-axis current response to step input.

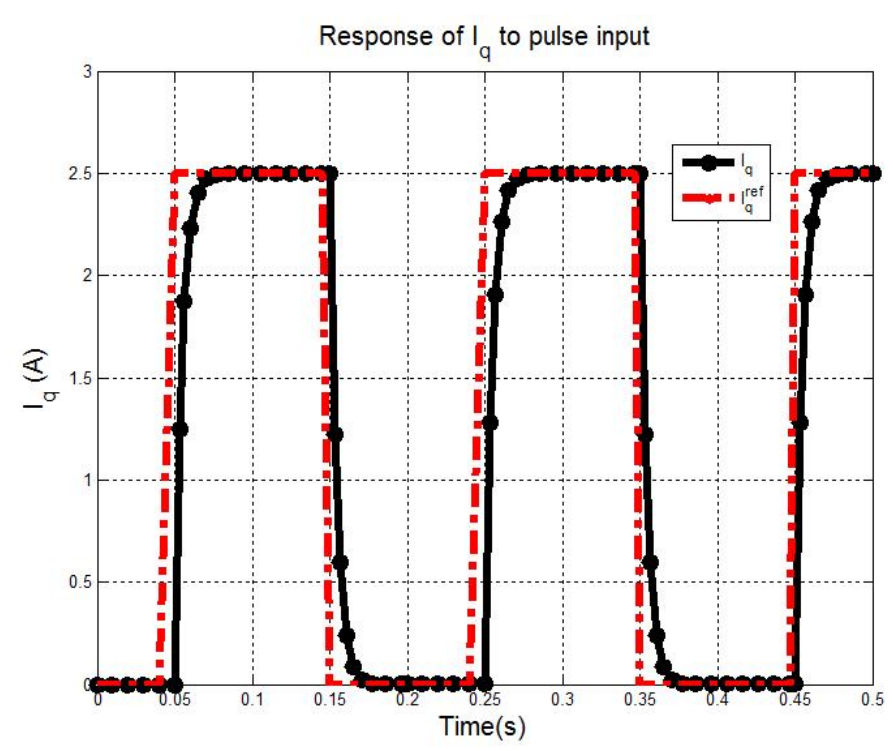

(a) Q-axis current response.

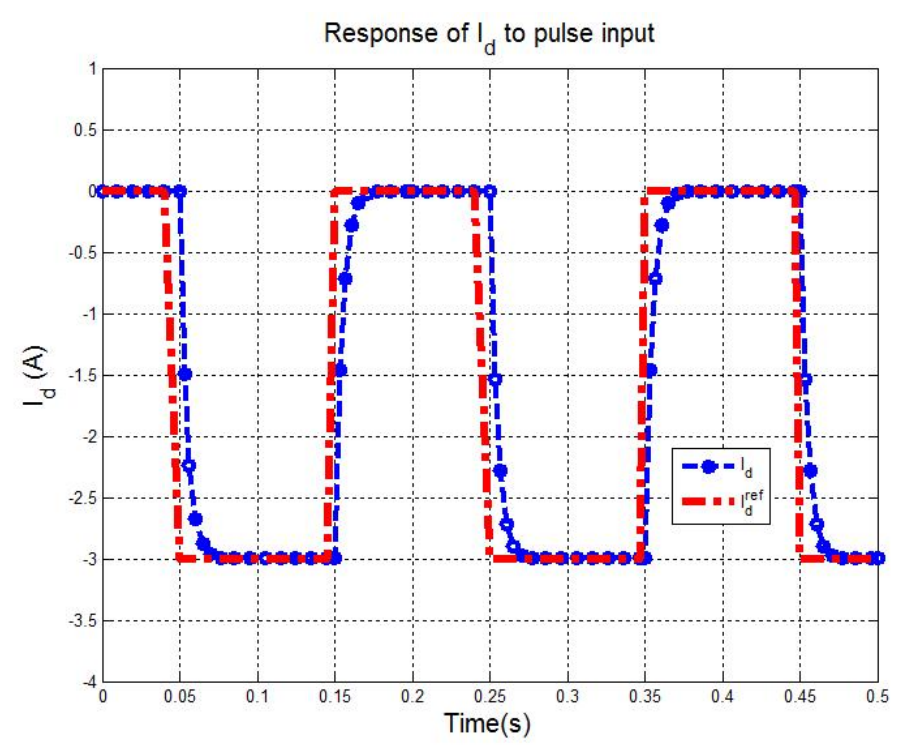

(b) D-axis current response to pulse input.

Figure 10: (a) Q-axis current response (b) D-axis current response to pulse input. 


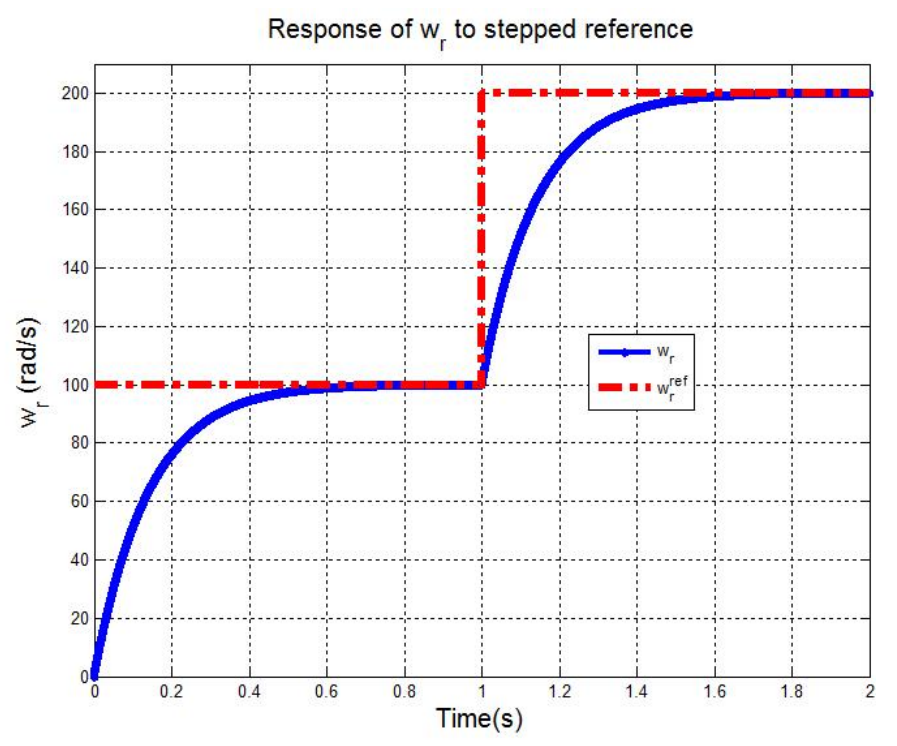

(a) Stepped input

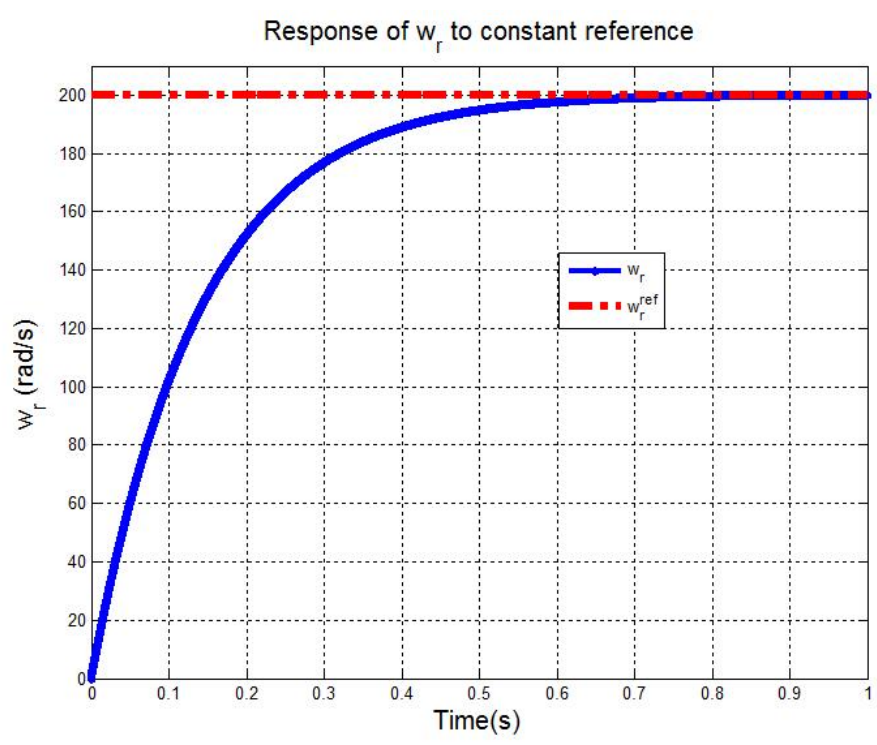

(b) Constant input.

Figure 11: Speed response to (a) stepped input (b) constant input.

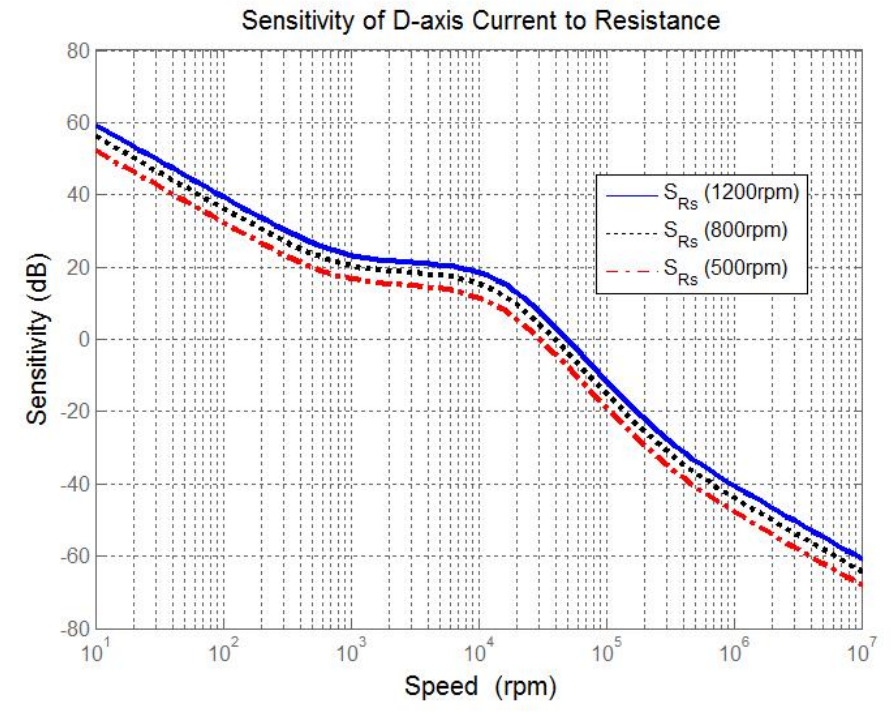

(a) D-axis current

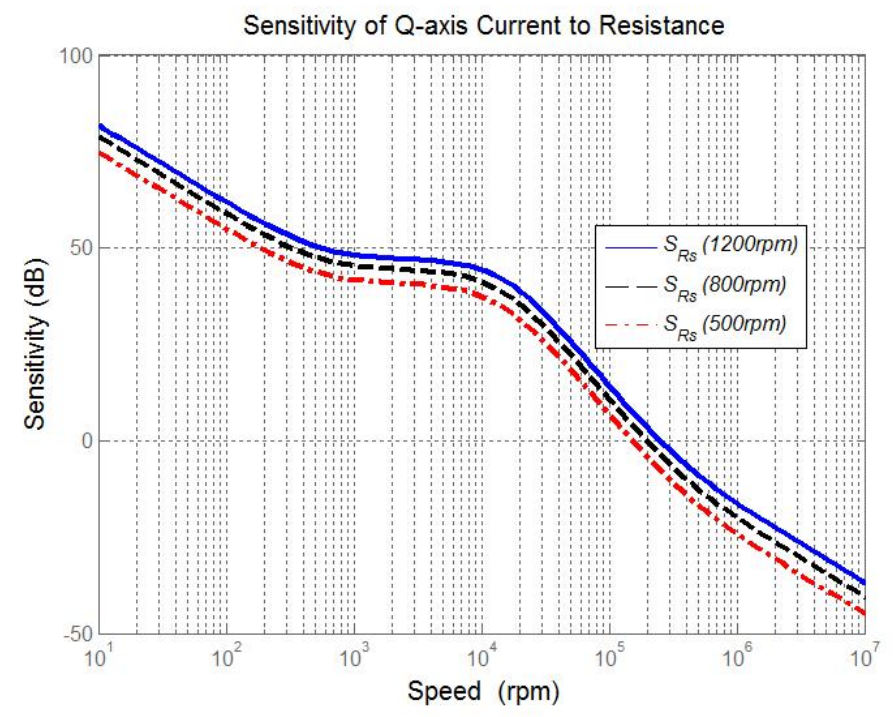

(b) Q-axis current to resistance

Figure 12: Sensitivity of (a) D-axis current (b) Q-axis current to resistance. 


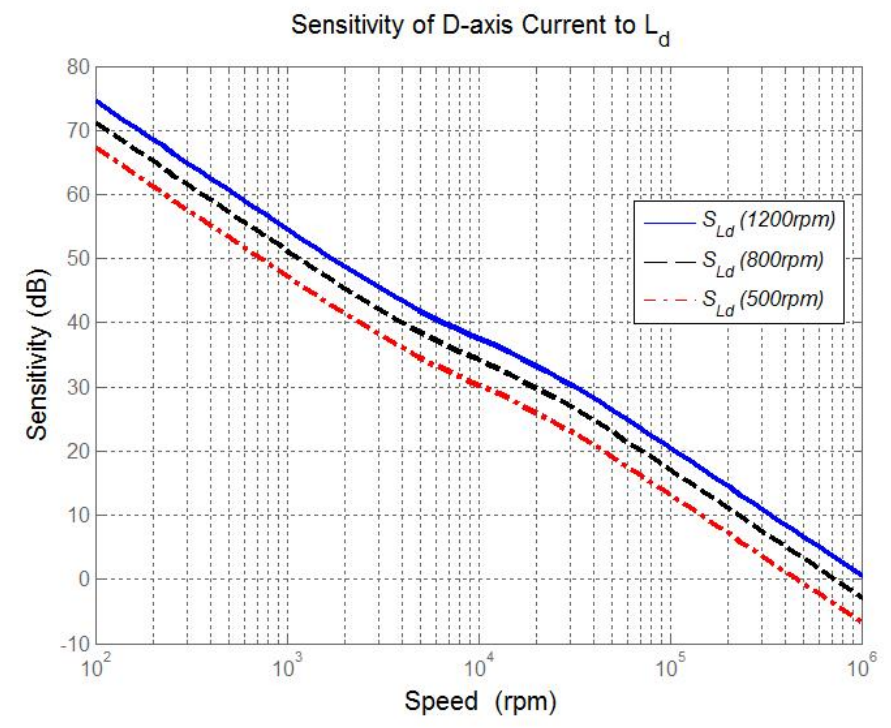

(a) D-axis current $L_{d}$

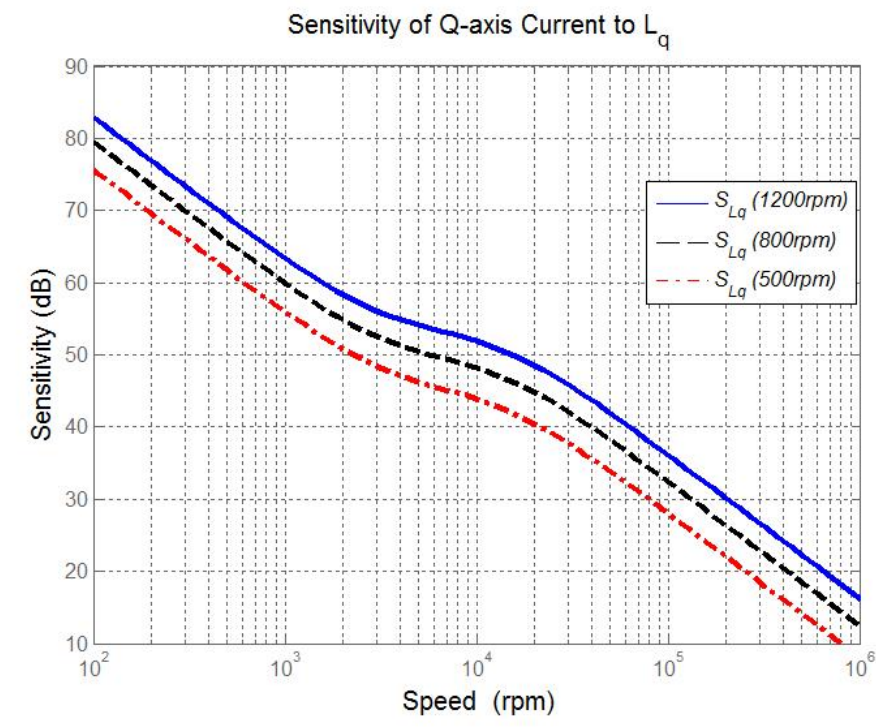

(b) Q-axis current to inductance $L_{q}$.

Figure 13: Sensitivity of (a) D-axis current $L_{d}$ (b) Q-axis current to inductance $L_{q}$.

similar characteristic is observed with the Q-axis current controlled by internal model control seen in Fig. 12(b). There is very low sensitivity of the current to changes in the resistance in the vicinity of the operational speed. In both cases seen in Fig. 12, the magnitude of sensitivity increases as speed goes from 500rpm to 1200rpm.

In Fig. 13, it is seen that currents in both $\mathrm{D}$ and Q- axes are highly sensitive to changes in $L_{d}$ and $L_{q}$ respectively at all frequencies of operation. The magnitude of the sensitivity is also higher as the speed of the machine increases. This is due to the fact that inductance is directly proportional to frequency. It is important to state that from Eq. (42), it is evident that $I_{d}$ is insensitive to $L_{q}$ and $I_{q}$ is insensitive to $L_{d}$.

\section{CONCLUSION}

An efficiency optimization scheme for an IPMSM that minimizes the copper, iron and stray losses was developed. Using analytic methods, a $4^{\text {th }}$ order equation was derived to obtain the optimum values of currents in the $d$ - and q-axes for the IPMSM. Current and speed control of the IPMSM were achieved by the internal model control method.

The simulation results obtained using MATLAB/SIMULINK reveal that the total losses dissipated with the loss minimization control are more reduced than the losses from the common method of torque control that sets the d-axis current to zero. Furthermore, the losses are observed to increase with speed. The loss minimization scheme developed produces efficiency gains of $0.2 \%$ to $1.5 \%$ in the IPMSM for as speed varies from 100-1500 rad/s. In addition, current sensitivity to machine parameters agree with the literature on other methods of current control.
The advantage of the proposed control scheme is that it saves memory cost that would have been required for the mapping table of optimal currents. In addition, it is not limited by the bandwidth of the system as obtained in online search methods.

\begin{tabular}{|ll|}
\hline Nomenclature \\
Symbol & Variable \\
$\lambda_{f}$ & field flux \\
$L_{d}$ & $d$-axis self-inductance \\
$L_{m d}$ & $d$-axis magnetizing inductance \\
$p$ & Differentiation operator \\
$T_{e}$ & Electromagnetic torque \\
$c_{f e}$ & Iron loss coefficient \\
$P_{s}$ & Stray loss \\
$R_{a d}, R_{a q}$ & Active damping \\
$B$ & coefficient of viscous damping \\
$\omega_{r}$ & rotor angular speed \\
$i_{q}^{r}$ & $q$-axis stator current \\
$L_{s}$ & stator inductance \\
$L_{q}$ & $q$-axis self-inductance \\
$L_{m q}$ & $q$-axis magnetizing inductance \\
$P$ & Number of poles \\
$P_{f e}$ & Iron loss \\
$P_{c u}$ & Copper loss \\
$P_{t}$ & Total power loss \\
$N_{p}$ & Number of pole pairs \\
$R_{s}$ & stator resistance \\
$i_{d}^{r}$ & $d$-axis stator current \\
$i_{d}^{r *}$ & $d$-axis stator reference current \\
$i_{q}^{r *}$ & $q$-axis stator reference current \\
$V_{d s}^{r}$ & $d$-axis stator voltage \\
$V_{q s}^{r}$ & $q$-axis stator voltage \\
$\lambda_{d s}^{r}$ & $d$-axis stator flux \\
$\lambda_{q s}^{r}$ & $q$-axis stator flux \\
\hline &
\end{tabular}




\section{References}

[1] E. Sarani and S. Vaez-Zadeh, "Line start permanent magnet motors with double-barrier configuration for magnet conservation and performance improvement," Electric Power Applications IET, vol. 11, no. 9, pp. 1656-1663, 2017.

[2] J. Liu, C. Gong, and Z. Wu, "Influence research of rotor structure parameters on the performance of ipmsm," in Electrical Machines and Systems (ICEMS) 2017 20th International Conference, 2017, pp. 1-5.

[3] D. Zhang, H. Dai, and H. Zhao, "A fast identification method for rotor flux density harmonics and resulting rotor iron losses of inverter-fed induction motors," in Industrial Electronics IEEE Transactions, vol. 65, no. 7, 2018, pp. 5384-5394.

[4] N. Denis, S. Odawara, and K. Fujisaki, "Attempt to evaluate the building factor of a stator core in inverterfed permanent magnet synchronous motor," in IEEE Transactions on Industrial Electronics, vol. 64, no. 3, March 2017, pp. 2424-2432.

[5] Q. Li, T. Fan, and X. Wen, "Characterization of iron loss for integral-slot interior permanent magnet synchronous machine during flux weakening," in IEEE Transactions on Magnetics, vol. 53, no. 5, May 2017, pp. $1-8$.

[6] J. Lee, K. Nam, S. Choi, and S. Kwon, "Loss-minimizing control of PMSM with the use of polynomial approximations," IEEE Trans. Power Elect., vol. 24, no. 4, pp. 1071-1082, 2009.

[7] J. Choi, S. Heo, and M. Kim, "Hybrid operation strategy of wind energy storage system for power grid frequency regulation," in IET Generation, Transmission \& Distribution, vol. 10, no. 3, 2016, pp. 736-749.

[8] J. Liu, T. Nondahl, P. Schmidt, S. Royak, and T. Rowan, "Generalized stability control for open-loop operation of motor drives," in IEEE Transactions on Industry Applications, vol. 53, no. 3, May-June 2017, pp. 2517-2525.

[9] S. Morimoto, Y. Tong, Y. Takeda, and T. Hirasa, "Loss minimization control of permanent magnet synchronous motor drives," IEEE Trans. Ind. Electron, vol. 41 , no. 5 , pp. 511-517, 1994.

[10] M. Rahman and M. Uddin, "Third harmonic injection based nonlinear control of ipmsm drive for wide speed range operation," 2017 IEEE Industry Applications Society Annual Meeting, Cincinnati, OH, 2017.

[11] G. Gallegos-Lopez, F. Gunawan, and J. Walters, "Optimum torque control of permanent-magnet AC machines in the field-weakened region," IEEE Trans. Ind. Appl., vol. 41, no. 4, pp. 1020-1028, 2005.

[12] M. Li, H. Tan, H. Cai, Y. Gao, and S. Li, "Online maximum efficiency control based on MRAS for unmanned air vehicle surface-mounted high-speed PMSM," 2017 Chinese Automation Congress (CAC), Jinan, 2017.

[13] B. Gallert, G. Choi, K. Lee, X. Jing, and Y. Son, "Maximum efficiency control strategy of PM traction machine drives in GM hybrid and electric vehicles," in 2017 IEEE Energy Conversion Congress and Exposition (ECCE), Cincinnati, OH, 2017, pp. 566-571.

[14] R. Chabaana and L. Wang, "Control of electrical power assist systems: design, torque estimation and structural stability," JSAE Review, vol. 22, no. 1, pp. 435$444,2001$.

[15] O. Wallmark, "Control of permanent magnet synchronous machines in automotive applications," Ph.D. dissertation, Chalmers University of Tech., 2006.

[16] L. Harnefors and H. Nee, "Model-based current control of AC machines using the internal model control method," IEEE Trans. Ind. Appl., vol. 34, no. 1, pp. 133$141,1998$.

[17] O. Babayomi, A. Balogun, and C. Osheku, "Loss minimizing control of PMSM for electric power steering," in proc. 2015 17th UKSIM-AMSS Int. Conf. Mod. and Sim., Cambridge, UK,, March 2015, pp. 438-443. 